\title{
The Application of SiC in Converter Steelmaking
}

\author{
Hailing Li ${ }^{1, a}$, Qichun Peng ${ }^{1, b}$,Youhua Wang ${ }^{2}$ \\ ${ }^{1}$ school of Material and Metallurgy, Wuhan University of Science and Technology,China. \\ ${ }^{2}$ Hunan Valin Xiangtan iron and Steel Co. Ltd. \\ a1lihailing@sina.com, bpengqichun1964@163.com
}

\begin{abstract}
Key words: Silicon carbide converter deoxidation mechanical properties inclusions
\end{abstract}
\begin{abstract}
Silicon carbide has better deoxidization ability than ferrosilicon and recarburizer by the thermodynamic analysis, the gas of $\mathrm{CO}$ produed by the deoxidation reaction can agitates molten steel which could purify the molten steel .In this article, we choose HRB400 as our testing steel, it is found that the usage of $\mathrm{SiC}$ can reach the aim of recarburization and silicon increasing in the statistical analysis, the various properties of the testing steel are stable, and the use of Silicon carbide can further improve the economic benefits of steel plants as the price of $\mathrm{SiC}$ is lower.
\end{abstract}

\section{Introduction}

Silicon carbide with the molecular weight of 40.07 and the density of $3.209 \mathrm{~g} / \mathrm{cm}^{3}$ is a kind of synthetic compounds, molecular formula is $\mathrm{SiC}$. SiC is made from high quality quartz sand and petroleum coke in the resistance furnace, it can be used as compound deoxidizer in metallurgy field as its widespread application. $\mathrm{SiC}$ is a new kind of compound deoxidizer with more stable physical and chemical performances and good deoxidization effection as the replacement of the traditional solid silicon powder and carbon powder.Furthermore, the usage of $\mathrm{SiC}$ has a cost advantage in reducing the consumption of raw materials and can improve the quality of the steel comparing with the original process. ${ }^{[2-5]}$ Since $\mathrm{SiC}$ has the traits of instability which is obvious under high temperature and oxidizing atmosphere, it is active in the environment of high temperature, and silicon will have the priority of reaction with oxygen in steel as silicon has stronger reducibility compared with manganese element ${ }^{[1]}$, which reduces the oxygen content in steel and the loss of the manganese element caused by dyoxidation. SiC has larger affinity to oxygen compared with silicon accompanying with strong reaction,which retains the alloies of $\mathrm{Si}$ and $\mathrm{Mn}$ in the liquid steel, improving the yield rates of the $\mathrm{Si}$ and $\mathrm{Mn}$. Therefore, the applications of $\mathrm{SiC}$ in the converter steelmaking process can achieve the purpose of cost decreasing and benefit increasing. Solid $\mathrm{SiO}_{2}$ and gaseous $\mathrm{CO}$ generated continuously accompany with the deoxidization reaction of $\mathrm{SiC}$ in the molten steel, which can agitates the molten steel constantly, the generation and floation of $\mathrm{CO}$ can promote the combination between solid $\mathrm{SiO}_{2}$ and other oxides such as $\mathrm{Al}_{2} \mathrm{O}_{3}, \mathrm{MnO}$ etc., which will purify molten still in certain extent.

\section{Thermodynamic Analysis of Silicon Carbide Deoxidization Process}

We can infer from the equations ${ }^{[1]}$ :

$$
\begin{array}{ll}
\mathrm{Si}_{(l)}+2[O]=\mathrm{SiO}_{2(s)} & \Delta G^{0}=-711489+202.84 \mathrm{~T}, \mathrm{~J} / \mathrm{mol} \\
C_{(s)}+[O]=C O_{(g)} & \Delta G^{0}=-2510-80.17 \mathrm{~T}, \mathrm{~J} / \mathrm{mol} \\
\mathrm{SiC}_{(l)}+3[\mathrm{O}]=\mathrm{SiO}_{2_{(s)}}+\mathrm{CO}_{(g)} & \Delta G^{0}=-2510-80.17 \mathrm{~T}, \mathrm{~J} / \mathrm{mol}
\end{array}
$$

the relationship between the temperature $\mathrm{T}$ and the standard gibbs free energy in above equations (2-1), (2-2), (2-3) can be drawn into a figure below : 


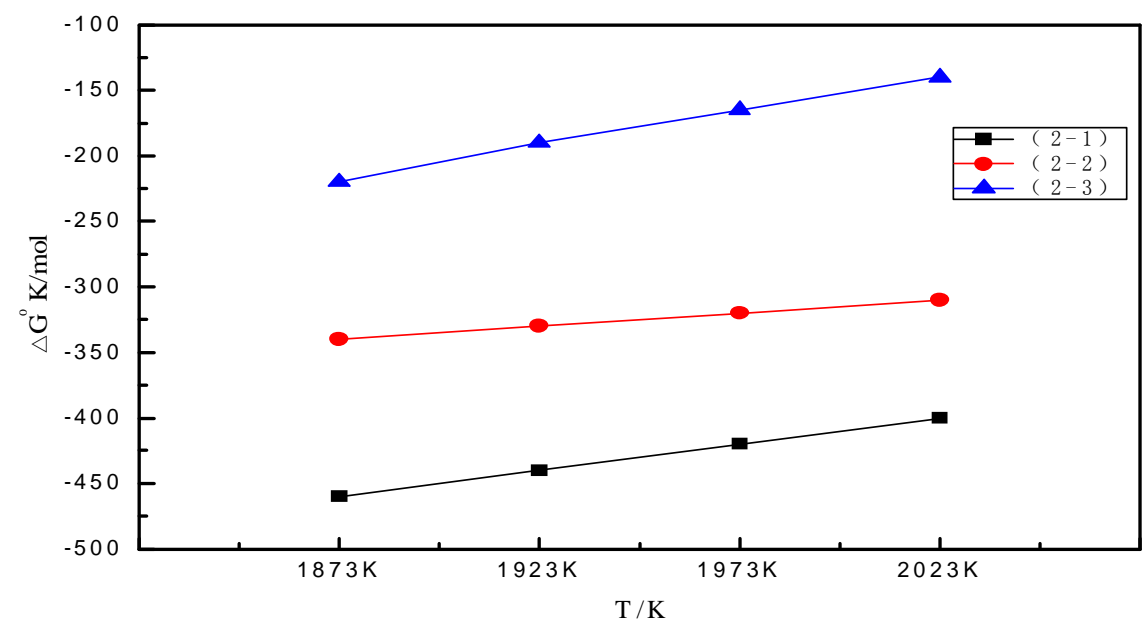

Fig. 1 the relationship between temperature $\mathrm{T}$ and standard gibbs free energy

in the temperature range of $[1873 \mathrm{~K}-2023 \mathrm{~K}]$, the rank of deoxidization abilities of the three materials from strong to weak is that: the Silicon carbide $(\mathrm{SiC})>\operatorname{Silicon}(\mathrm{Si})>$ Carbon $(\mathrm{C})$.

\section{The analysis of deoxidization abilities of Silicon carbide}

Theoretically, The consumption of deoxidizer can be concluded from the ratio of deoxidizing elements and the oxygen's atomic weight combining with them. The reaction can be expressed as follows:

$$
x R+y O=R_{x} O_{y}
$$

It is inferred from the above formulas that when using silicon as desoxidant the calculation is that:

$$
\begin{aligned}
& {[\mathrm{Si}]+2[\mathrm{O}]=\left(\mathrm{SiO}_{2}\right)} \\
& \frac{\Delta[\mathrm{Si}]}{\Delta[\mathrm{O}]}=\frac{M_{S i}}{2 M_{O}}=\frac{28}{2 \times 16}=0.875
\end{aligned}
$$

When choosing recarburizer as desoxidant:

$$
[C]+[O]=C O \quad(2-7) \quad \frac{\Delta[C]}{\Delta[O]}=\frac{M_{C}}{M_{O}}=\frac{12}{16}=0.75
$$

When choosing the mixture of Ferrosilicon and Recarburizer by the ratio of $2: 1$ as desoxidant, The unit consumption is that:

$(0.875) \times 2+0.75 / 3=0.833$

When choosing silicon carbide as desoxidant:

$$
\begin{aligned}
& {[\mathrm{SiC}]+3[\mathrm{O}]=\left(\mathrm{SiO}_{2}\right)+\mathrm{CO}} \\
& \frac{\Delta[\mathrm{SiC}]}{\Delta[\mathrm{O}]}=\frac{M_{(\mathrm{C}+\mathrm{Si})}}{3 M_{O}}=\frac{12+28}{3 \times 16}=0.833
\end{aligned}
$$

It is can be included that the theoretical deoxidization consumption is identical between the mixture of Ferrosilicon and recarburizer by the ratio of $2: 1$ and Silicon carbide as desoxidant. 


\section{Industrial Experiment}

Based on the above analysis and theoretical support, we will put silicon carbide into 120 ton converter plant to testify its effect by adding silicon carbide $250 \mathrm{~kg}$ per furnace, aimming to increase $\mathrm{C}$ to $0.08 \% \sim 0.10 \%$ and $\mathrm{Si}$ to $0.12 \%$. Because of its effect is not clear, SiC will only be allowed to be added into the steel of HRB400, and other grades of steel are prohibited to be added into. According to the three principles of alloy adjustment in the literature ${ }^{[2]}$, the alloy adjustment scheme is showed below.

Table 1 the alloy adjustment scheme

\begin{tabular}{lll}
\hline Steel grade & the original process & the new process \\
\hline HRB400 & FeMn+FeSi+AlMnTi $+\mathrm{VN}$ & $\mathrm{FeSi}+\mathrm{MnSi}+\mathrm{SiC}+\mathrm{SiAlBa}+\mathrm{VN}$ \\
\hline
\end{tabular}

The addition way of silicon carbide is that FeSiMn and $\mathrm{SiC}$ alloy should be added when the molten steel tap to $1 / 3$ of the total molten steel .

When the weight percent of $\mathrm{SiC}$ is under $70 \%$ in Silicon carbide alloy, the $\left(\mathrm{SiO}_{2}+\mathrm{Si}\right)$ free is so many that will increase the contents of gases and inclusions and even lead to a sharp increase of $\mathrm{T}[\mathrm{O}]$ and inclusions in molten steel,in comparison, the addition of $\mathrm{SiC}$ alloy which contains $\mathrm{w}(\mathrm{SiC})$ up 75\% has no obvious effects on the content of gases and inclusions in molten steel,and it is uneconomical when adding the Silicon carbide alloy containing $\mathrm{SiC}$ up $90 \%$ in weight percent. ${ }^{[2 / 5]}$ Therefore, the physical and chemical components requirements for Silicon carbide alloy are listed as follows.

Table 2 Chemical components for Silicon carbide alloy

\begin{tabular}{ccccccc}
\hline & \multicolumn{9}{c}{$\mathrm{W}_{\mathrm{B}} / \%$} & & & $\begin{array}{c}\text { particle } \\
\text { size/mm }\end{array}$ \\
\hline $\mathrm{SiC}$ & $\mathrm{Si}_{\text {free }}$ & $\mathrm{C}_{\text {free }}$ & $\mathrm{P}$ & $\mathrm{S}$ & $\mathrm{H}_{2} \mathrm{O}$ & $\leq 5$ \\
\hline $82 \sim 88$ & $4 \sim 10$ & $\leq 1.50$ & $\leq 0.05$ & $\leq 0.05$ & $\leq 0.50$ & $\leq 5$ \\
\hline
\end{tabular}

Table 3 the chemical components of HRB400

\begin{tabular}{cccccccc}
\hline & $\mathrm{C} \%$ & $\mathrm{Si} \%$ & $\mathrm{Mn} \%$ & $\mathrm{P} \%$ & $\mathrm{~S} \%$ & $\mathrm{~V} \%$ & $\mathrm{Ceq}$ \\
\hline $\begin{array}{l}\text { National } \\
\text { standard }\end{array}$ & $\leq 0.25$ & $\leq 0.80$ & $\leq 1.60$ & $\leq 0.045$ & $\leq 0.045$ & $\leq 0.12$ & $\leq 0.54$ \\
$\begin{array}{l}\text { Internal } \\
\text { standard }\end{array}$ & $0.17 \sim 0.25$ & $0.40 \sim 0.60$ & $1.20 \sim 1.60$ & $\leq 0.045$ & $\leq 0.045$ & $0.03 \sim 0.12$ & $0.43 \sim 0.54$ \\
\hline
\end{tabular}

\section{The experimental results and related statistics}

This experiment contains 74 furnaces, and the conditions of alloies added are listed in tables 1 to 3.the statistics of practical $\mathrm{Si}$ and $\mathrm{C}$ increased by $\mathrm{SiC}$ are depicted into figures below:

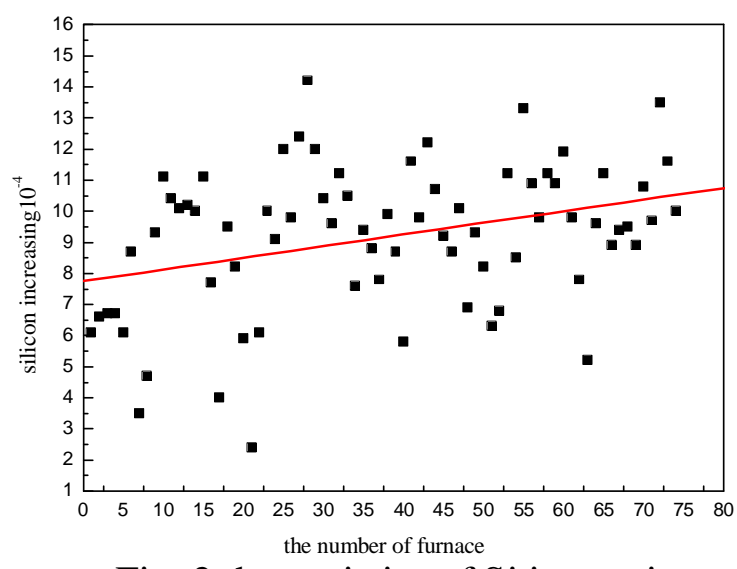

Fig. 2 the statistics of Si increasing

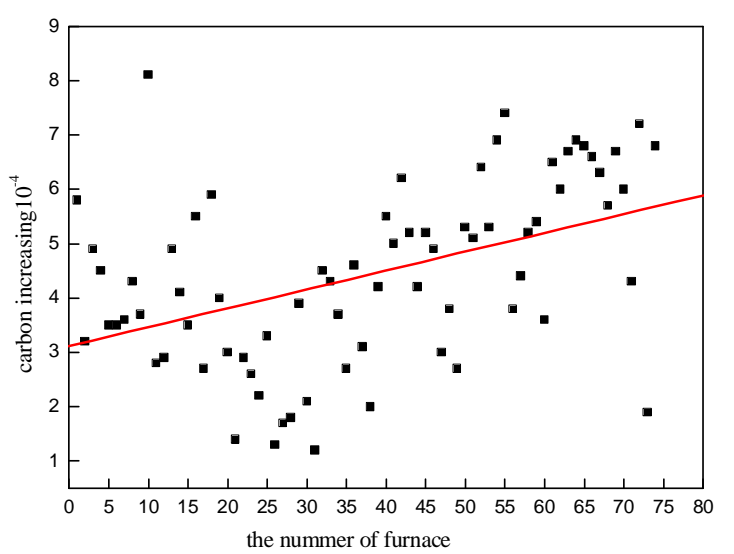

Fig. 3 the statistics of $\mathrm{C}$ increasing 
We can see from the figure above, this experiment result is consistent with the experiment of $\mathrm{Li}$ Yonggang, etc. ${ }^{[2]}$

Steel mechanical properties including yield strength, tensile strength and elongation are related to steel composition, technological parameters such as rolling temperature, in order to objectively analyze the affection of original technology and new process on the quality of the steel, the final point control of converter and the rolling temperature process have not changed,based on the analyzation of the steel produced by the new and the original deoxidation alloying process, its mechanical performance indexes are shown in table 4.74 furnaces HRB400 steel are produced by new process, and the diameter of rolled steel is $\Phi 22 \mathrm{~mm}$. All HRB400 steel mechanical properties are qualified, and the steel strength of HRB400 has increased about $10 \mathrm{MPa}$,just as the table 4 shows .Finally,the internal quality of the steel gets improved.

Table 4 the mechanical properties comparison of steel produced by this two processes

\begin{tabular}{cccccccc}
\hline \multirow{2}{*}{$\begin{array}{c}\text { Steel } \\
\text { grade }\end{array}$} & items & \multicolumn{3}{c}{ average value } & \multicolumn{3}{c}{ mean square error } \\
\cline { 3 - 8 } & & $R_{\mathrm{eL} / \mathrm{MPa}}$ & $R_{\mathrm{m} / \mathrm{MPa}}$ & elongation & $R_{\mathrm{eL} / \mathrm{MPa}}$ & $R_{\mathrm{m} / \mathrm{MPa}}$ & elongation \\
& new process & 481 & 658 & 25.9 & 14.3 & 17.9 & 0.9 \\
\multirow{3}{*}{ HRB400 } & original & 469 & 645 & 25.1 & 21.8 & 28.7 & 2.1 \\
& $\begin{array}{c}\text { process } \\
\text { comparison }\end{array}$ & +12 & +13 & +0.8 & -7.5 & -10.8 & -1.2 \\
\hline
\end{tabular}

The steel produced by this two process are tested randomly by high and low power optical microscopes, the macroscopic examination result shows that the maximum center loose is grade 1 , no other defects are found. high power microscopic examination results is showed in Table5, from the metallographic observation, we can see that the steel group and grain size are denser and smaller. Comprehensive results show that the steel internal organization is normal, the quality is fine.

Table 5 Metallographic inclusions comparison of HRB400 produed by two process.

\begin{tabular}{|c|c|c|c|c|c|c|}
\hline \multirow{2}{*}{$\begin{array}{l}\text { Alloying } \\
\text { process }\end{array}$} & \multirow{2}{*}{$\begin{array}{l}\text { Sample } \\
\text { number }\end{array}$} & \multicolumn{5}{|c|}{ Metallographic inclusion/grade } \\
\hline & & $\begin{array}{l}\text { Sulfide thin } \\
\text { department }\end{array}$ & $\begin{array}{l}\text { Silicate thin } \\
\text { department }\end{array}$ & $\begin{array}{l}\text { Silicate } \\
\text { coarse } \\
\text { department }\end{array}$ & $\begin{array}{l}\text { Globular } \\
\text { oxide thin } \\
\text { department }\end{array}$ & $\begin{array}{l}\text { Globular } \\
\text { oxide coarse } \\
\text { department }\end{array}$ \\
\hline New alloying & 10 & $0.5-1.0$ & $0.5-1.5$ & $0.5-1.0$ & $0.5-1.5$ & $0.5-1.0$ \\
\hline & 10 & 0.7 & 0.9 & 0.6 & 0.7 & 0.6 \\
\hline Original & & $0.5-1.0$ & $0.5-2.0$ & $0.5-1.5$ & $0.5-2.0$ & $0.5-1.0$ \\
\hline $\begin{array}{l}\text { alloying } \\
\text { process }\end{array}$ & 10 & 0.7 & 1.0 & 0.7 & 0.8 & 0.8 \\
\hline
\end{tabular}

\section{Conclusions}

the deoxidation of $\mathrm{SiC}$ can reduce the loss of manganese element in steel, and has a certain effect of increasing the contents of Carbon and Silicon in molten steel, improving the yield rate of Silicon and Manganese and purifying molten steel as $\mathrm{CO}$ generated by deoxidization reaction escapes out.

Within the scope of the steelmaking temperature, the deoxidization ability of Silicon carbide is the strongest, carbon's deoxidization ability is the weakest.

It is reasonable when choosing silicon carbide to replace Silicon and Carburant,which can decrease the cost of deoxidation.

various properties of the steel of HRB400 are stable when choosing silicon carbide as the deoxidizer and alloy. 


\section{References}

[1] Zhang Chaoyang,Ju Jiantao,etc. the Experimental Research of Sic Deoxidation in Converter, Si Chuan Metallurgy,2001, (1), p. 14

[2] Li Yongang,Huang Daochang, etc. the Production Practice of Carbide Alloying in Converter Steelmaking, Steel making Dec. 2006, 22(6), p.9-11

[3] Yang Huaichun, et al. the Impact Analysis of Sic Deoxidation Alloying in Converter Steelmaking, Xin Jiang Metallurgy, 2014,(2), p.45

[4] Chenwei,Suzhe, et al. Adopting MnSi + SiC Alloying Production Practice of Hot Rolled Ribbed Steel Bar, Steel making Dee. 2009,25 (6), p. 32

[5] Nie Yuqing. Process Optimization Study of 20MnSi Steel in Deoxidation Alloying,2000,(4), p. 21 